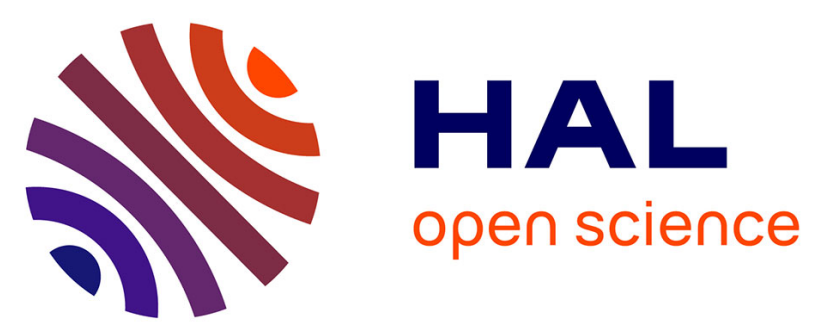

\title{
Design and operationalization of patterns: Case of a training situation of personal assistance for public in professional integration
}

Lahcen Oubahssi, Claudine Piau-Toffolon, Jean-Pierre Clayer, Fatma

Kammoun

\section{To cite this version:}

Lahcen Oubahssi, Claudine Piau-Toffolon, Jean-Pierre Clayer, Fatma Kammoun. Design and operationalization of patterns: Case of a training situation of personal assistance for public in professional integration. 8th Int. Conf. on Software Technologies (ICSOFT'13), Jul 2013, Reykjavik, Iceland. pp.488-495. hal-01433264

\section{HAL Id: hal-01433264 \\ https://hal.science/hal-01433264}

Submitted on 24 Aug 2018

HAL is a multi-disciplinary open access archive for the deposit and dissemination of scientific research documents, whether they are published or not. The documents may come from teaching and research institutions in France or abroad, or from public or private research centers.
L'archive ouverte pluridisciplinaire HAL, est destinée au dépôt et à la diffusion de documents scientifiques de niveau recherche, publiés ou non, émanant des établissements d'enseignement et de recherche français ou étrangers, des laboratoires publics ou privés. 


\title{
Design and operationalization of patterns: Case of a training situation of personal assistance for public in professional integration
}

\author{
Lahcen Oubahssi ${ }^{1}$, Claudine Piau-Toffolon ${ }^{1}$, Jean-Pierre Clayer $^{1}$, Fatma Kammoun ${ }^{1}$ \\ ${ }^{1}$ LIUM, IUT de Laval, 52 Rue des drs Calmette et Guérin, F-53020 Laval Cedex 9 France \\ firstName.lastName@univ-lemans.fr
}

\begin{abstract}
Keywords: Technology-Enhanced-Learning Systems, Pattern, Pedagogical Scenario, Operationalization, Professional integration, Training Development, Instructional Design.

Abstract: The research presented in this paper aims to offer support to the activity of designing to teacher or a community of teachers by a context-sensitive tool exploiting a library of patterns. This paper presents work carried out in the context of a partnership with an association (PARTAGE) promoting the professional integration of the jobseekers. This work aims to make a contribution to assist the association pedagogical team (trainers and designers) to formalize the pedagogical scenarios describing their learning situations. We analyzed their process guiding the jobseeker course and formalized some of their training practices in the form of patterns. We have studied the feasibility of operationalizing techniques in a learning management system platform like Ganesha.
\end{abstract}

\section{INTRODUCTION}

In France, as in many countries, the training needs for the professional integration of jobseekers continue to evolve in all domains, because training is a factor of social progress, technological development and economic growth. Whether presential, distance or hybrid, professional training is required to innovate, to gain interest and efficiency. Changing the apprentices requirements brought new challenges. It is in particular to provide training solutions combining educational effectiveness and the participants involvement. These issues, combined with the current socio-technological context, turn towards more use of new learning support and Learning Management Systems (LMS). This approach necessarily influenced the practicing teachers and trainers responsible for identifying new teaching strategies within training organizations.

This paper presents a research realized as part of a partnership with an association (PARTAGE) promoting the jobseekers professional integration. This work aims to make a contribution to assist the association pedagogical team (trainers and designers) to formalize the pedagogical scenarios describing their learning situations. The findings motivating this research are: the growing need for the association pedagogical team to formalize scenarios describing computerized educational situations, the nonadequacy of the educational modeling languages (EML) (Koper \& Tattersall, 2005) (Vignollet \& al, 2006) for a public of designers and the low level of reuse of existing educational practices.

The main objective of this work is to help the teacher / trainer and his community to control the mediated learning situations. For this purpose, we propose to provide tools and methods to assist them all along their instructional design process. To this end, this research builds on the work of the educational re-engineering of Technology-EnhancedLearning (TEL) systems (Choquet, 2007), a patternbased visual approach (Hernandez -Leo \& al, 2010) and learning scenarios operationalization (Oubahssi $\&$ al, 2010). Our aim is to specify and formalize learning scenarios and the learning pedagogical language used to express them as patterns for their operationalization. To carry out this work, we studied the existing educational practices of the association, which enabled identifying a process, we call it jobseekers course. We present this process in section 3 of this document, we describe in particular an example of pedagogical activity of the process ie the 
individual evaluation/ training session. This analysis also helped us to identify the various concepts related to the pedagogical language of the association trainers. We present the results of this formalization and its operationalization in section 4. Our design approach is guided by an engineering design process framework based on patterns. Before presenting this result, we present in section 2 the theoretical framework of our design approach. Finally, we conclude this paper with a discussion related to work and prospects.

\section{RESEARCH CONTEXT}

Many research works propose models, methods or design tools to analyze, implement and operate models describing learning situations with scenarios (Alexander \& al, 1977)(Vignollet \& al, 2006) (Martel \& Vignollet, 2007)(Oubahssi \& al, 2010). Learning Scenarios are designed according two types of approaches. The first one is a well-known modeling approach based on Educational Modeling Languages (EML), as the IMS Learning Design specification (Koper \& Olivier, 2004) leads to enable the design of computational models (in the meaning of understandable by a computer) which could be enacted by compliant systems. However these specifications are not really usable by teachers and do not enforce design processes that support the creation of pedagogically sound designs (Hernandez -Leo \& al, 2010). A second approach is to allow designers (may be assisted by modeling specialists) to define their own EML by specifying a domain-specific language and to use it for building their scenarios (El Kechaï $\&$ Choquet, 2007) while ensuring the possibility of translation of the formalism to a standard language. This approach permits to exceed the expressiveness limits of the previous one (Kelly, 2007). Our research work is based on this second approach. We propose a teachers centered design approach and state that teachers are able to build their learning scenarios by the use of patterns. We intend to help a teacher/trainer or a community of teachers/ to formalize their educational needs in the form of patterns and operationalize in TEL (TechnologyEnhanced-Learning) systems without any assistance of a pedagogical engineer or an expert.

\subsection{Design and Patterns}

The pattern approach is not new. Patterns have been used in the late seventies in the field of building architecture, by (Alexander \& al, 1977). Several repositories of patterns exist for various disciplines and offer design expertise reuse to the corresponding communities. In particular, in design based research education, a pattern's approach is well-suited as it is sensitive to complexity and context-dependence (Mor \& Winters, 2007). According to Laurillard's works (Laurillard, 2012), this approach is immediately relevant to teachers as it presents means by which a community can participate in design. This formalism offer the opportunity to the teacher to externalize his knowledge (Goodyear, 2005) and it can be formally expressed.

Patterns are semi-structured description of an expert's method for solving a recurrent problem which includes a description of the problem itself and the context in which the method is applicable (Mor \& Winters, 2007). They capture the best practices to answer to problems in a particular context. By their formalism, patterns support the design creativity without constraints. Users are guided rather than forced in the use of patterns (Rohse \& Anderson, 2006). In the literature, many types of patterns has been developed to solve different kind of problems: analysis patterns, implantation patterns, process patterns, architecture patterns and design patterns. Their formalisms differ depending of the type of problems to solve. In educational and TEL domain, many projects as Pedagogical Patterns Project (PPP, 2011) or Design Patterns for recording and analyzing Usage of Learning Systems (DPULS - Kaleidoscope Learning Patterns project) (DUPLS, 2005) proposed a catalogue of patterns which concern learning strategies types of problem. So pedagogical practitioners, especially inexperienced designers, during the design stage, through use of catalogue of patterns can take advantage of previous design expertise (E-LEN / Pedagogical Patterns Collector) (ELEN, 2012) (Delozanne \& al, 2007).

Researchers in education get increasing interest with pattern-based design approach. COLLAGE, a collaborative learning flow pattern (CLFP) editor (Hernandez-LeoO \& al, 2006) proposes a pattern based visual design approach implemented in RELOAD. This approach is based on the IMS LD specification which enables the modeling of learning processes. The MDEduc project proposes a Pedagogical Patterns Editor for the design of learning scenario using the formalism and syntax of patterns (De Moura, 2007). ScenEdit and the model ISIS support also a pattern based approach to design learning scenarios (Emin \& al, 2008).

These approaches present interesting methodological way to formalize or interpret different learning issues but some limitations and shortcomings have 
been identified to deal with the practicing teachers design activity. Patterns are not always well-suited to the learning design situation. Teachers cannot express their needs with their own business language. The lack of sharing, reuse strategy and learning design processes support and guidance are other shortcomings of those existing approaches. Our approach will provide help to teachers in the building of their solution step by step with patterns as scenario chunks, according to their own design approach, called pedagogical design schemes. Teachers are free to express patterns in their own business language (e.g. pedagogical concepts and method) (El Kechaï \& Choquet, 2007).

A pedagogical situation is composed of different elements defining a scenario: Learning strategies, Learning situations, Objectives, Activities, Human resources, Material resources. We take into account these elements within four categories of pedagogical problem: Activity design, Learning situations design, Resources design and Pedagogy design. According to the design problems highlighted in teaching domain, (Clayer \& al, 2012) explored the TEL engineering domain best practices (Mor \& Winters, 2007)(Mor, 2010)(Laurillard, 2012)(Rohse \& Anderson, 2006) (Bergin \& al. 2012) and the software engineering patterns solutions implemented in the information system domain (Fowler, 1997) (Amber, 98) (Gamma \& al, 95). These authors identified four formalisms of patterns to solve the four types of problem: Pedagogical patterns; Analysis Patterns, Process Patterns and Design Patterns. (Clayer \& al, 2012) defined a pattern's metamodel describing a language for composing or merge the different patterns. This metamodel conforms to MOF (Meta-Object Facility), is used to generate an editing tool. We used this metamodel to formalize the educational scenarios of different situations of the PARTAGE association within the learning concepts in use in the community of trainers. Our aim is to operationalize patterns and scenario resulting in an TEL systems.

\subsection{Operationalization of pedagogical scenarios}

The operationalization of the learning scenarios consists in implementing teachers-intended scenarios on one TEL environment. It resumes some manipulations as creation of activities, selection of participants, allocation of roles and selection of required services and content for scenarios (e.g. pedagogical resources) (Martel \& Vignollet, 2007). However, the operationalization of learning scenar- ios is not only an engineer activity. It aims to translate teacher's intention and relative pedagogical semantics on a TEL system. There are two types of approaches to operationalize pedagogical scenarios: a manual approach and an automated approach. (Abedmouleh \& al, 2011) classified the existing approaches to operationalize into four categories: Standard oriented approach (as IMS-LD (De Vries $\&$ al, 2006) or CopperCore (Berggren \& al, 2005); Practitioners oriented approaches (as COLLAGE (Hernández \& al, 2006) or LDL (Martel \& al, 2007); Approaches proposed for specific platforms (as LAMS (Delziel \& al, 2006)) and Hybrid approaches based on Model Driven Engineering techniques (as Bricoles (Caron \& al, 2005)).

The analysis of these approaches leads us to observe that The different proposed solutions do not fit with the teachers-designers needs. The COLLAGE proposition is interesting because the collaborative design patterns proposed to practitioners have been specified and developed on top of the IMS-LD standard: semantics about concepts/relations transformations have been taken into account when building the patterns; these patterns are fully-compatible with IMS-LD. In the other hand, operationalizing COLLAGE models relies on operationalizing IMSLD ones. Unfortunately, most of existing platforms are still not compatible with this standard (Berggren $\&$ al, 2005) (Burgos \& al, 2007). We describe in this paper an example of formalization and operationalization (automated approach) of a learning situation based on a pattern design approach.

\section{PEDAGOGICAL PRACTICES ANALYSIS OF "PARTAGE" ASSOCIATION}

To analyze the pedagogical practices of the association "PARTAGE", we have participated in various workshops set up to accommodate the jobseeker. This analysis is carried out into three steps. The first step is to clarify the association needs. The aim of this step is on the one hand to improve the supports of the existing training approach, but also to permit the introduction of computerized training. The public is composed of adults most of the time not always comfortable with trainings and traditional paper and pencil assessment test. They often have low education level, have difficulty to express themselves, are sometimes illiterate or do not speak the language of the country. The training needs range from the evaluation of capacity and competencies of 
the people arriving in the association to the professional learning certification.

In a second step, we prepared a questionnaire in which we highlighted the different phases of the accompanying process of the jobseeker (performances referred, solutions, resources used, association challenges, public, skills, training objectives, functioning of the association,...). In a third time, we have carried out the pedagogical practices of the association on the basis of the questionnaire. For the purposes of the survey, we assisted to several formative assessment sessions / training proposed by the association to future members. Following this discussion, we have identified a set of information about: the goal of each phase and the major steps as well as the issues discussed; the tools and supports used; the date, the frequency, the duration of each step; the participants, their numbers, their role; the pedagogical concepts covered; the problems and difficulties for trainers and jobseeker and solutions addressed; the pedagogical approach used; the approach and the rhythm imposed; the structure of the training, its contents; the type of support, the assessment, the activities, the criteria for success, etc. The study and analysis of the results of this survey allowed to identify and describe the different phases of the jobseekers course (Fig. 1).

\subsection{The jobseekers course}

To facilitate the jobseekers professional integration, the PARTAGE association proposes an accompaniment process illustrated in Fig.1. The jobseeker arrives to the association home service where it is proposed to benefit from personalized assistance until it can be integrated into the labor force. If he/she is interested by the PARTAGE services, he/she follows a predefined process which consists essentially of three main phases: The first phase consists in the registration process. It is composed of three phases. The objective of the first step is to inform the jobseekers about the association and its functioning and permits to the pedagogical team to make an initial assessment of the jobseekers. The second phase is an individual interview, during which the trainer evaluates the jobseekers motivation degree to work in the domestic employment, to identify the constraints, to be aware of the importance of training, to be evaluated in work environment, to identify their strengths and weaknesses, etc. In a third time, the PARTAGE pedagogical team studies and validates the jobseekers registration form. Then as a members of the association he may follow the rest of the process. The pedagogical team will specify the training course and formative assessment session will be proposed before the employment.

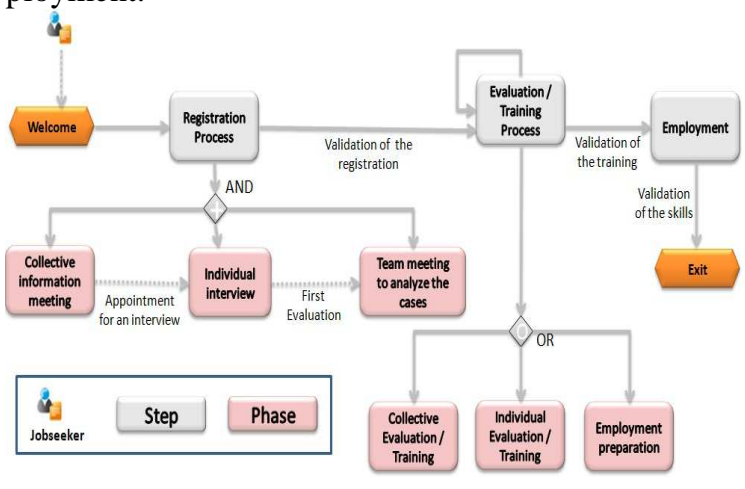

Figure 1 : The jobseekers course.

The second step is the jobseekers evaluation / training, it can be conducted in several ways depending on the capacity and the competencies of jobseekers. There are three types of training : the individual training in the presence of the jobseekers and trainer, the collective training with presence of the trainer and a group of six people maximum. These first two types of training can occur in a theoretical way in a classroom and / or in the practical situation of the pedagogical apartment. The third type of training consists in preparation to go back to work. It can take the form of an oral interview where the trainer provides educational resources to the jobseekers that will serve them in their employment.

The third step is the employment. At this level, several types of evaluations / training can be proposed: the validation of professional skills, a support specific to the jobseekers, etc. After the validation of professional skills, the jobseeker may leave PARTAGE partially while maintaining contact with the association or definitely when reintegrated in a professional environment. In some special cases, the jobseekers may move to a direct employment after an initial interview and a pedagogical team decision. In other cases, the jobseekers can participate in several types of training and as much as necessary before their employment. In case where it seems impossible to the jobseeker adapt to the job proposed, the PARTAGE pedagogical team may decide to refuse the jobseeker registration and orients him /her to other structures of help.

The analysis of pedagogical practices of PARTAGE helped to define the objectives of the association, to identify the problematic and propose solutions to improve existing scenarios. We chose to detail in the following section, the example of the individual evaluation/training session. 


\section{EXAMPLE OF FORMALIZATION AND IMPLEMENTATION OF A LEARNING SITUATION}

\subsection{Description of an individual evalua- tion/training session}

A jobseeker who would like a domestic employment proposed by the association may /have to follow a learning session before its employment. The learning scenario of this session is composed of many phases intertwining theoretical and practical activities (done in a pedagogical apartment). The activities of this session are organized according to the motivation of the jobseekers. The table below (Table 1) illustrates the main phases of the session progress.

Table 1 : Main phases of the individual evaluation/training session

\section{Phase 1 : Individual positionnement interview}

The trainer use the individual positioning interview to define the jobseeker's course in order to organize the session and its content according to its skills. He/she gives some recommendations to explain some basic concepts in relation to PARTAGE. Then he/she proposes a first assessment based on paper-and-pencil test. This kind of learning exercise is a sort of "skills assessment".

Phase 2: Analyzing and answering to questions

According to candidate skills (writing and reading), the test is operated alone or accompanied. Some exercises are explained to the job seeker (questions that may be not clear, without influencing the answers). This intervention may be as neutral as possible. Other exercises are realized as practical evaluation in a pedagogical apartment using necessary tools and products to realize the mission.

\section{Phase 3 : Correction}

The correction is progressing in two steps : the first one is done on the basis of interviews centered on apprenticeship 's difficulties. It offers the possibility to the trainer with the jobseeker to analyze the problem situation in order to identify the causes and choose a relevant and effective remediation. During the second session, the trainer ensure the monitoring of the jobseeker, try repeat the erroneous part of the test to measure the impact of the adjustment and help build their apprenticeship to a higher level.

Phase 4: Synthesis of the individual summative evaluation After the evaluation correction and the achievement of practical activities, the trainer propose a summative evaluation of the jobseeker where he/she can note some points identified during discussions with the jobseeker during the training session as punctuality, communication control, following the instructions, organization, control of different techniques specific to the required job.

\subsection{Analysis of the individual evalua- tion/training session}

The analysis of this session permit identifying the following difficulties : (1) Training scenarios are paper-based and limiting their evolution and reuse as trainers are often changing. (2) An assortment of strategies and tools, from questions' reading to direct assistance is required to adapt to an adult varied audience. (3) The training materials used by learners are not sufficiently expressive, often expressed in ambiguous terms or not into usual vocabulary of jobseekers, requiring trainers to offer more help during the training session. This context raises the question of adaptability of the training material to the audience. (4) At the end of each session, a summative evaluation is done on paper or in part transformed into digital format. The jobseeker follow-up is not easy in the long term.

To improve instructional practices and supports with intend of improving pedagogical practices of the individual evaluation training session, we should develop a computer artefact that meets the following requirements: (1) Capitalize on the experience and skills acquired by the jobseekers during their training course, in order to use the resulting knowledge. In a technology enhanced learning environment, a formative evaluation for training approach should permit to record the jobseekers skills required for the job during training activities. This can permit further to validate these skills and provide a certificate of skills acquisition to the job seekers. (2) Another objective could be the stabilization of the PARTAGE process (reuse of learning contents) ; (3) Capitalization of the trainers know-how ; (4) Improving the knowledge and information supply of the association (providing a attestation/certificate to validate the skills, the jobseekers training course, the support, etc.) ; (5) Use of different training supports (photo, video sound, animation, etc.) and, (6) Adapting existing support for future audiences.

\section{FORMALIZATION OF THE INDIVIDUAL EVALUATION / TRAINING SESSION}

We based the design and formalization of the individual formative assessment training session on the patterns' metamodel of (Clayer \& al, 2012) and its process design framework. They identify four patterns types: pedagogical pattern, analysis pattern, process pattern and design pattern. Each pattern is 
associated to a pedagogical element of a learning situation (objective and strategy, activity, human and material resource, actor role). To design a learning scenario, a trainer or a teacher can design a solution with the four types of patterns proposed with the metamodel. Trainers/ practicing teachers may follow an iterative design process framework (Clayer \& al, 2012) supported by an editing tool, composed of four main steps: specification of the pedagogical needs, creation/choice of patterns, merge or composition of patterns, collect of the design context information and adaptation of the solution to this context. In the following, we present an example of a design session in the case of an individual formative evaluation training session. We present two patterns resulting from this design session. The first one formalizes the training progress and the second one the creation of an assessment test.

\subsection{Specification of the pedagogical needs}

Trainer has to define the different elements of its pedagogical situation in terms of objectives/goals, resources, pedagogical strategy, actors and roles, etc.

Objectives/goals definition: The objective of the session is to evaluate/assess the jobseekers according to the following points: making the difference between different domestic employments, respecting hygiene standards, taking appropriate initiatives, be able to properly organize the tasks required, etc.

Definition of pedagogical resources: Within the session, a resource or a pedagogical tool may be : module content, training room, pedagogical apartment, paper based support for training session, real tools and cleaning products, etc.

Definition of a strategy: To provide a general presentation of the session, assessment of the job seeker level, formative evaluation, summative evaluation of the jobseeker (its weaknesses and strengths), etc.

Definition of the actors and roles: The two main actors participating to the session are the trainer and the job seeker.

\subsection{Creation / Selection of Patterns}

To design scenario of the training session, we create patterns associated to each elements of the training situation. We present in this section two examples of patterns.

The first one, a design pattern describes the evaluation session phases from the trainer's point of view. Formalism of design pattern needs the specification of the following items: problem, motivation, context, participants, collaboration between participants, solution, consequences and implementation of the session.

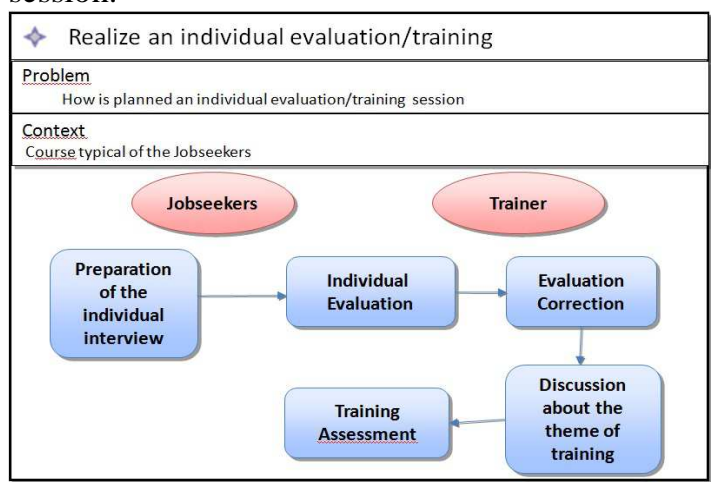

Figure 2 : Design pattern of the individual training session.

The figure 2 gives a « simple » representation of the design pattern (specifying only three items: problems, context and solution on a graphical format). It describes in the solution part the training evaluation session activities and sub-activities.

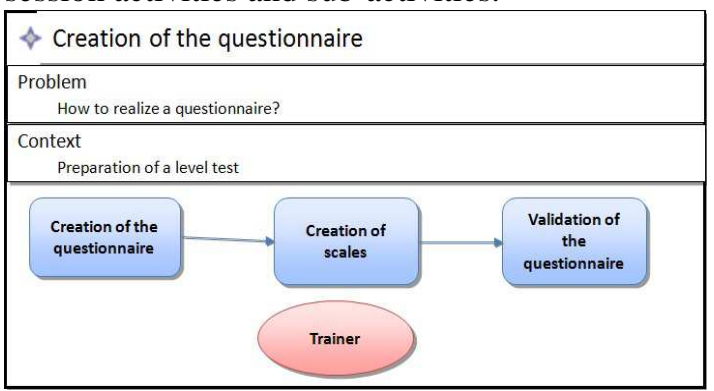

Figure 3: Process pattern for questionnaire creation

The second figure (figure 3) represents an example of process pattern. It formalizes an evaluation test creation in the current individual evaluation training session. This simplified representation describes the solution (in a graphical form) of the elaboration/preparation of the training session. The solution permits the elaboration of a level test by a questionnaire. These two patterns take place in the accompaniment process of a jobseeker. This process is represented within a more general pattern illustrating the solution of the association to the problem of organization of the jobseeker accompaniment process. The formalization of the different training session of a jobseeker is based on patterns creation design activity. Each pattern proposes a solution for some pedagogical situation. In the next section, we study the feasibility of the operationalization of a learning scenario based on patterns : Creation of a test on the Ganesha platform. 


\section{OPERATIONALIZATION}

Before trying to develop a TEL systems that takes into account the current teaching practices of the PARTAGE association, and their future needs, we studied with the PARTAGE educational team the various existing solutions, especially two systems Moodle (Moodle) and Ganesha (Ganesha). The analysis of these platforms has enabled to choose the platform Ganesha as a test environment to experiment the operationalization of different patterns that formalize the training session and individual assessment. The choice of the PARTAGE educational team is explained by the ergonomic and functionality of the system Ganesha that appear to meet the needs in the overall process of the jobseekers. After studying the different solutions to test the patterns implementation that formalize the training and evaluation session, we opted for the following solution:

- Generate a pattern in XML format via the patterns' editor (Clayer \& al, 2012). In this case, we seek to operationalize the quiz pattern by a questionnaire (Fig. 4),

- Develop a GANESHA internal service which can import and operationalize this XML file.

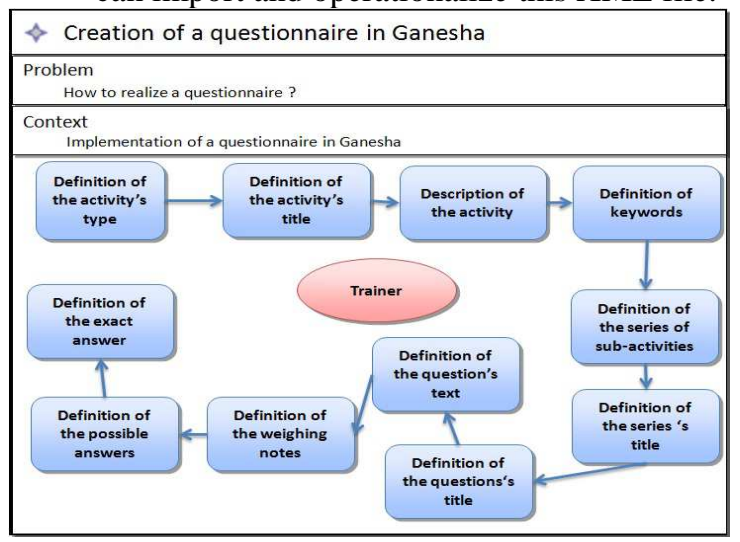

Figure 4: Pattern process: Create questionnaire in GANESHA

The operationalization process is described in four steps illustrated in Figure 5. The first step defines the scenario (eg, a scenario which formalizes the evaluation creation). The second step formalizes this scenario in the XML-formatted file using the patterns editor. The third step applies the transformation rules on the XML file that conforms to the use of GANESHA platform schema, and the fourth step imports the XML file (after the application of transformation rules) in the platform data base, which provides a new scenario on this platform.

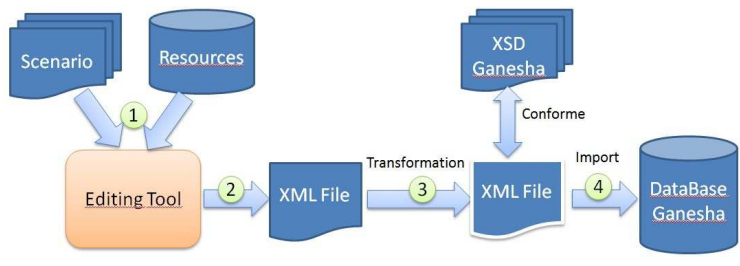

Figure 5: Operationalization process of design pattern in GANESHA

\section{CONCLUSION}

The aim of this work is to help the teacher / trainer and his community to control the mediated learning situations. In this paper, we addressed the problem of the specification and instructional design using patterns in the field of the professional training. The aim of the research work is to propose a support for the design activity of a teacher or a community of teachers by a context-sensitive tool exploiting a library of patterns. The design process proposes teachers to design learning situation from patterns according to their own design approach identified as pedagogical design scheme. The PARTAGE association dealing with professional integration in the domestic employment, provided to us a field of experimentation. We analyzed their process guiding the jobseekers course and formalized some of their pedagogical practices in the form of patterns. We studied the technical feasibility of the operationalization to a Ganesha platform. Further works consist in the development of methods and tools in order to better support the trainers' learning design activity. We intend to experiment our approach and the reuse of the patterns in other learning contexts. We are currently studying the operationalization of some activities of their general process on tablets (operationalization of the jobseekers intake form and some formative assessment test).

\section{REFERENCES}

Abedmouleh, A; Laforcade, P; Oubahssi, L; Choquet, C; 2011. Operationalization of learning scenarios on existent Learning Management Systems: the Moodle casestudy. In International Conference on Software and Data Technologies, Seville, Spain, pp.143-148, 18-21 july 2011.

Alexander, C., Sara Ishikawa, S., Silverstein, M., Jacobson, M., Fiksdahl-King, I. and Angel. S. 1977. A pattern language: town, buildings, construction. New York: Oxford University Press. 
Amber, S. W., Process pattern - building large-scale systems using object technology, Cambridge University Press, ISBN 0-521-645668-9. (1998)

Bergin, J; Eckstein, J; Völter, M; Sipos, M; Wallingford, E; Marquardt, K; Chandler, J; Sharp, H; Lynn Manns, M. (2012). Pedagogical Patterns: Advice for Educators, Pedagogical Pattern Editorial Board. Published by Joseph Bergin Software Tools.

Berggren, A., Burgos, D., Fontana, J.M., Hinkelman, D., Hung, V., Hursh, A., Tielemans, G.,2005. Practical and Pedagogical Issues for Teacher Adoption of IMS Learning Design Standards in Moodle LMS. In Teacher Adoption of IMS Learning Design Standards in Moodle LMS. Journal of Interactive Media in Education, 2005.

Burgos, D., Tattersall , C., Dougiamas , M., Vogten , H., Koper, R., 2007. A First Step Mapping IMS Learning Design and Moodle . Journal of Universal Computer Science, vol. 13, no. 7 (2007), 924-931

Caron, P.A., Derycke, A., Le Pallec, X., «Bricolage and Model Driven Approach to design distant course », In E learn 2005, world conference on E-learning in corporate Government, HealthCare \& highter education, 2005.

Choquet, C, 2007. Ingénierie et réingénierie des EIAH : l'approche REDiM, Habilitation à diriger des recherches en informatique, Université du Maine 2007.

Clayer, JP., Piau-Toffolon, C., Choquet, C,. 2012. A pattern-based and teacher-centered approach for learning design", In Computers and Advanced Technology in Education, 2012

Dalziel, J. 2003. Implementing Learning Design: The Learning Activity Management System (LAMS), retrieved January 16, 2013 from http://www.lamsinternational.com/documents/ASCILI TE2003.Dalziel.Final.pdf.

Delozanne E., Le Calvez F., Merceron A. , Labat J-M,. 2007. "A Structured set of Design Patterns for Learners' Assessment". Journal of Interactive Learning Research, Vol 18, $\mathrm{N}^{\circ} 2$, pp. 309--333.

De Moura Filho C.O. 2007. Conceiving and Implementing a language-oriented approach for the design of automated learning scenarios, thesis, 2007

De Vries, F., Tattersall, C. Koper, R. 2006. Future developments of IMS Learning Design tooling. IN Educational Technology \& Society, 9 (1), 9-12, 2006.

DPULS.2005. Design Patterns Browser, Action du réseau d'Excellence Européen Kaleidoscope, 2005

E-LEN. 2012. European project - Minerva programs: http://www2.tisip.no/E-LEN/

El Kechaï H, Choquet C . Reusing Pedagogical Scenarios at a Knowledge Level: a Model Driven Approach. The 7th IEEE International Conference on Advanced Learning Technologies (ICALT'2007), isbn : 0-76952916-X, Niigata (Japan), p.670-674, July 18-20, 2007

Emin, V., Pernin, J.-P., \& Guéraud, V. 2008. Times of Convergence. Technologies Across Learning Contexts, Lecture Notes In Computer Science, chapter ISiS: An Intention-Oriented Model to Help Teachers, 2008, Learning Scenarios Design. vol. 5192, 338-343
Fowler, M., Analysis Patterns, Addison-Wesley, Reading MA. (1997)

Gamma, E, Helm R., Johnson R. and Vlissides J., Design Patterns: Elements of Reusable Object-Oriented Software. Addison-Wesley. ISBN 0-201-63361-2. (1995)

GANESHA : http://www.ganesha.fr/

Goodyear, P.. Educational design and networked learning: Patterns, pattern language and design practice. Australasian Journal of Education Technology, 21(1) , 2005, 82-101.

Hernandez-Leo, D, Villasclaras-Fernández, E. D., Asensio-Pérez, J. I, Dimitriadis, Y., Jorrín-Abellán, I. M., Ruiz-Requies, I., \& Rubia-Avi, B. (2006). COLLAGE: A collaborative Learning Design editor based on patterns. Educational Technology \& Society, 9 (1), 58-71

Hernandez-Leo D., Jorrın-Abellan I.M. , VillasclarasFernandez E.D., Asensio-Perez J.I., Dimitriadis Y., 2010. A multicase study for the evaluation of a pattern-based visual design process for collaborative learning. IN Journal of Visual Languages and Computing 21 (2010), p,313-331.

Kelly S., Domain Specific Languages vs. Generic Modelling Languages, interview may 2007 : http://www.ddj.com/architect/199500627

Koper, R. and Tattersall, C.,2005. Learning Design : A Handbook on Modelling and Delivering Networked Education and Training. Springer Verlag, 2005

Koper R, Olivier B., 2004. Representing the Learning Design of Units of Learning, Educational Technology \& Society, 7 (3), pp 97-111, 2004.

Martel, C., Vignollet, L., Ferraris, C., David, J.-P., Lejeune, A.,2007. Modeling collaborative learning activities on e-learning platforms. In: Proceedings of the Sixth IEEE International Conference on Advanced Learning Technologies, pp. 707-709, 2007.

Mor, Y. and Winters, N., Design approaches in technology enhanced learning, Journal of Interactive Media in Education.(2007)

Mor, Y. 2010., Embedding Design Patterns in a Methodology for a Design Science of e-Learning, in Christian Kohls \& Joachim Wedekind, ed., 'Problems Investigations of E-Learning Patterns: Context Factors Solutions', Information Science Publishing, Hershey, PA,

MOODLE : https://moodle.org/

Laurillard D, Teaching as a Design Science, Building Pedagogical Patterns for Learning and Technology, Routledge edition, 2012, ISBN 978-0-415-8038.

Oubahssi L, Laforcade P, Cottier P ., 2010. Reengineering of the Apprenticeship Electronic Booklet : Adaptation to new users requirements. IN 10th IEEEICALT Proceedings, Sousse (Tunisia), Juillet 2010.

PPP. 2011 Pedagogical Patterns Project: http://www.pedagogicalpatterns.org/

Rohse, S. Anderson, T, 2006, Design Patterns for Complex learning, Journal of Learning Design 2006.

Vignollet L., Ferraris C, David J.-P, Lejeune A. 2006. LDL: An Alternative EML. In Advanced Learning Technologies, 2006. Sixth International Conference 